\title{
Biochemical, ECF18R, and RYR1 Gene Polymorphisms and Their Associations with Osteochondral Diseases and Production Traits in Pigs
}

\author{
Haja N. Kadarmideen
}

Received: 16 March 2007/Accepted: 23 July 2007/Published online: 18 October 2007

(C) Springer Science+Business Media, LLC 2007

\begin{abstract}
This study reports the association of five blood types, three enzymes, two proteins, Escherichia coli F18 receptor gene (ECF18R), and the Ryanodin receptor $(R Y R l)$ gene with six production traits, four meat quality traits, and two osteochondral diseases in Swiss pig populations. Data on on-farm traits (daily weight gain, percent premium cuts, and backfat) and on station-tested traits (daily weight gain, feed conversion ratio, meat quality, and osteochondral lesions) were available on 3,918 and 303 animals, respectively. A mixed linear model with allele substitution effects was used for each trait by marker analysis (144 analyses). Significant marker-trait associations and allele substitution effects are presented. In general, heritability estimates for production and meat quality traits were higher than those for osteochondral lesions. Blood types lack significant associations with many traits except $\mathrm{H}$ and $\mathrm{S}$ types. Enzymes (mainly, glucose phosphate isomerase) and protein polymorphisms show significant associations with daily weight gain, premium cuts, and backfat as well as osteochondral lesions. The RYR and ECF18R genes significantly affected all growth, production, and lean meat content traits and osteochondral lesions; $R Y R$ also affected $\mathrm{pH}$ values. This study reports many novel marker-trait associations, particularly between the incidence of osteochondral lesions and polymorphisms at glucose phosphate isomerase, 6-phosphogluconate dehydrogenase, postalbumin $1 \mathrm{~A}, R Y R$, and ECF18R loci. These results should be useful in selection and for further functional genomics and proteomics investigations.
\end{abstract}

\footnotetext{
H. N. Kadarmideen

Institute of Animal Science, Swiss Federal Institute of Technology, ETH Zentrum, Zurich 8092, Switzerland

H. N. Kadarmideen ( $\square)$

CSIRO Livestock Industries, JM Rendel Laboratory, P.O. Box 5545, Mail Centre, Rockhampton, QLD 4702, Australia

e-mail: haja.kadarmideen@csiro.au
} 
Keywords $R Y R 1$ gene $\cdot E C F 18 R$ gene $\cdot$ Production traits $\cdot$ Osteochondrosis · Pigs

\section{Introduction}

The success of any breeding program depends on how many different economically important traits are considered in an optimal manner so as to improve efficiency of production. Pork production has moved from considering only lean meat, growth, feed efficiency, etc., to considering also health and meat quality. Historically, health and meat quality were not considered feasible breeding objectives because the heritability was low, they were difficult to measure, or they were not economically important. Since the advent of whole genome scans or quantitative trait locus (QTL) mapping in pigs, about 750 QTLs or major genes have been mapped by 2005, and the number of QTLs is still increasing. A database called PigQTLDB (Hu et al. 2005) constantly updates identified QTLs in pigs. Some of these QTLs affect health and meat quality traits in pigs. With the availability of such QTLs, the interest has increased in breeding pigs for health and meat quality using gene or marker-assisted selection, although they are difficult to improve by conventional breeding techniques.

Leg weakness is one of the major reasons for lameness leading to culling in gilts, sows, and boars, a syndrome characterized by changes in leg position and abnormal locomotion. Selection for production traits such as high growth rate and meat content are found to exacerbate leg weakness problems (Rothschild et al. 1988; Jørgensen 1995). The etiology of leg weakness is considered to be osteochondrosis, a generalized ossification in the joint cartilage as well as in the growth plates (Lundeheim 1987). These osteochondral lesions have a genetic basis and are inheritable by progeny generations with the polygenic heritability of $0.12-0.38$ (Kadarmideen et al. 2004). Further, osteochondral lesions show a mixed inheritance with a segregating major gene (Kadarmideen and Janss 2005).

The conventional biochemical markers (such as enzymes and proteins), blood types, and DNA tests can be used in animal breeding, if they have strong associations with the above-mentioned traits and osteochondral diseases. Such markers for complex traits would play an important role in emerging areas of integrated genetics, transcriptomics, and proteomics in the form of systems genetics of complex traits (Kadarmideen et al. 2006; Kadarmideen and Janss 2007) Vögeli et al. (1994) reported using European Landrace and Pietrain pigs segregating for malignant hyperthermia, C-T mutation at nucleotide (nt) 1843 in the skeletal muscle ryanodine receptor $(R Y R l)$ gene, earlier identified as the causal mutation for malignant hyperthermia (Fujii et al. 1991; Otsu et al. 1991; Houde et al. 1993). In another study of 236 pigs selected for resistance or susceptibility to edema disease, Vögeli et al. (1996) mapped the genes specifying receptors for F18 fimbriated Escherichia coli (ECF18R), causing this edema disease, to chromosome 6. Since the development of DNA tests for the RYR1 and ECF18R genes, all pigs in the Swiss pig breeding programs were tested and selected based on their genotype. In addition, 
some blood types, proteins, and enzyme systems are assayed for routine parentage control.

The RYRl gene polymorphism and its association with the frequency of PSE (pale, soft, exudative) pork is well established (e.g., Murray and Johnson 1998), along with a number of other meat quantity and quality measurements, such as leanness, muscling, $\mathrm{pH}$, reflectance, color, lactate content, and water holding capacity (e.g., Larzul et al. 1997; Lahucky et al. 1997). It would be useful to identify associations between these routinely typed gene/markers, including the $R Y R 1$ gene, and routinely recorded economically important traits, particularly for growth, meat quality, and osteochondral diseases. Such associations could also be used in more advanced systems biology and genetics investigations. Based on that background, the main aim of this study was to investigate and quantify the association of osteochondral lesions with blood types and polymorphisms in enzymes and proteins and in the ECF $18 R$ and $R Y R I$ genes. These associations are also reported for several growth and meat quality traits in Swiss pig populations.

\section{Materials and Methods}

\section{Pig Breeding Program and Trait Measurements}

Animals used in this study were from Suisag, a stock company for services in pig production, including herdbook, field and station tests, and artificial insemination ( http://www.suisag.ch). In the breeding program, Large White pigs are used as the sire line and the dam line, and Landrace pigs are used as the dam line in the nucleus herds. In the multiplier herds the two lines are crossed. The F1 sow is used in production herds. Large White and Duroc pigs are bred in nucleus herds and used as terminal sires in production herds. This breeding program with specialized sire and dam lines has been defined since 2000. Performance testing at the station is for production, reproduction, and type traits. Station tests are conducted for about 3,000 animals per year, via sib/progeny testing. Weight measurements on animals are taken at the beginning (around $30 \mathrm{~kg}$ ) and at the end (around $103 \mathrm{~kg}$ ) of the test. Animals are fed ad libitum in pen feeders (group size 10), and feed intake is known for a test litter but not for the individual pig. Feed conversion ratio (FCR) was defined as the ratio of weight of feed (in $\mathrm{kg}$ ) consumed to live weight gain (in $\mathrm{kg}$ ). The estimated individual feed intake was used to get an estimate of the individual FCR. All pigs are slaughtered at the test station, and carcass measurements are taken by trained technicians at the test station. Meat quality traits are measured in the $\mathrm{m}$. longissimus dorsi muscle at the 10th dorsal vertebra. Further details are given in Kadarmideen et al. (2004).

\section{Biochemical and DNA Marker Genotypes}

In the Suisag breeding program, animals are routinely genotyped at the $R Y R l$ and $E C F 18 R$ genes to select pigs against porcine stress syndrome and susceptibility to 
diarrhea, respectively. Blood groups typed were A, S, H, G, and E. Enzyme systems typed were glucose phosphate isomerase (GPI), 6-phosphogluconate dehydrogenase (PGD), phosphoglucomutase 2 (PGM), postalbumin 1A (Po1A), and $\alpha-1-\mathrm{B}$ glycoprotein (A1BG). The information on these markers dated from 1996 to 2003. Genotyping for polymorphisms in the RYRI and ECF18R genes was performed as per the method described by Vögeli et al. (1994, 1996). Typing of blood groups and other biochemical (enzyme and protein) polymorphisms is also described by Vögeli et al. (1996).

\section{Phenotypes and Pedigree}

Traits considered in this study (along with their abbreviations) are given in Table 1. Further details on recording and quantitative genetics of all traits and osteochondral lesions are described in Kadarmideen et al. (2004).

Briefly, osteochondral lesions were recorded by trained personnel in Suisag who conducted pathological examination of front and hind leg bones of slaughtered pigs. An affected humer joint is shown in Fig. 1. Osteochondral lesions were scored 1 (normal) and 4, 5, or 6 (severely affected), depending on the severity of the lesion. Figure 1 also shows seven positions on the bones where different lesions are scored. Only two of these lesions are considered here, the distal epiphyseal cartilage of the ulna (DEU) and condylus medialis femoris (CMF). Other lesions were not considered here because they were very rare; such low incidences in population genetic analyses can lead to spurious findings (e.g., Kadarmideen et al. 2000, 2001). Information on marker types was available for 3,918 animals recorded for on-farm traits and 303 animals recorded for stationtested traits and osteochondral lesions. A pedigree was constructed suitable for sire models with relationships among sires (523 sires in on-farm dataset and 113 sires in station-test data).

\section{Statistical Model and Analyses}

A mixed linear model estimated environmental/nongenetic and polygenic as well as allele substitution effects for each trait by each system:

$$
y=X \beta+W g+Z s+e
$$

where $y$ is a vector of records, $X$ is a design matrix relating fixed effects in $\beta$ to $y$. The fixed effects in the model involving osteochondral lesions, meat quality or quantity, daily weight gain, and feed conversion ratio are given in Table 1, along with number of records used for each trait. The design matrix $Z$ in the model relates records to random sire genetic effects in vector $s$. The vector $e$ contains residual effects.

There were 77 farms, 58 year and month of performance tests, three breed effects, and two sexes in the model for analysis of on-farm datasets. In the station test dataset, there were 36 stable periods and 86 slaughter days in slaughterhouse 


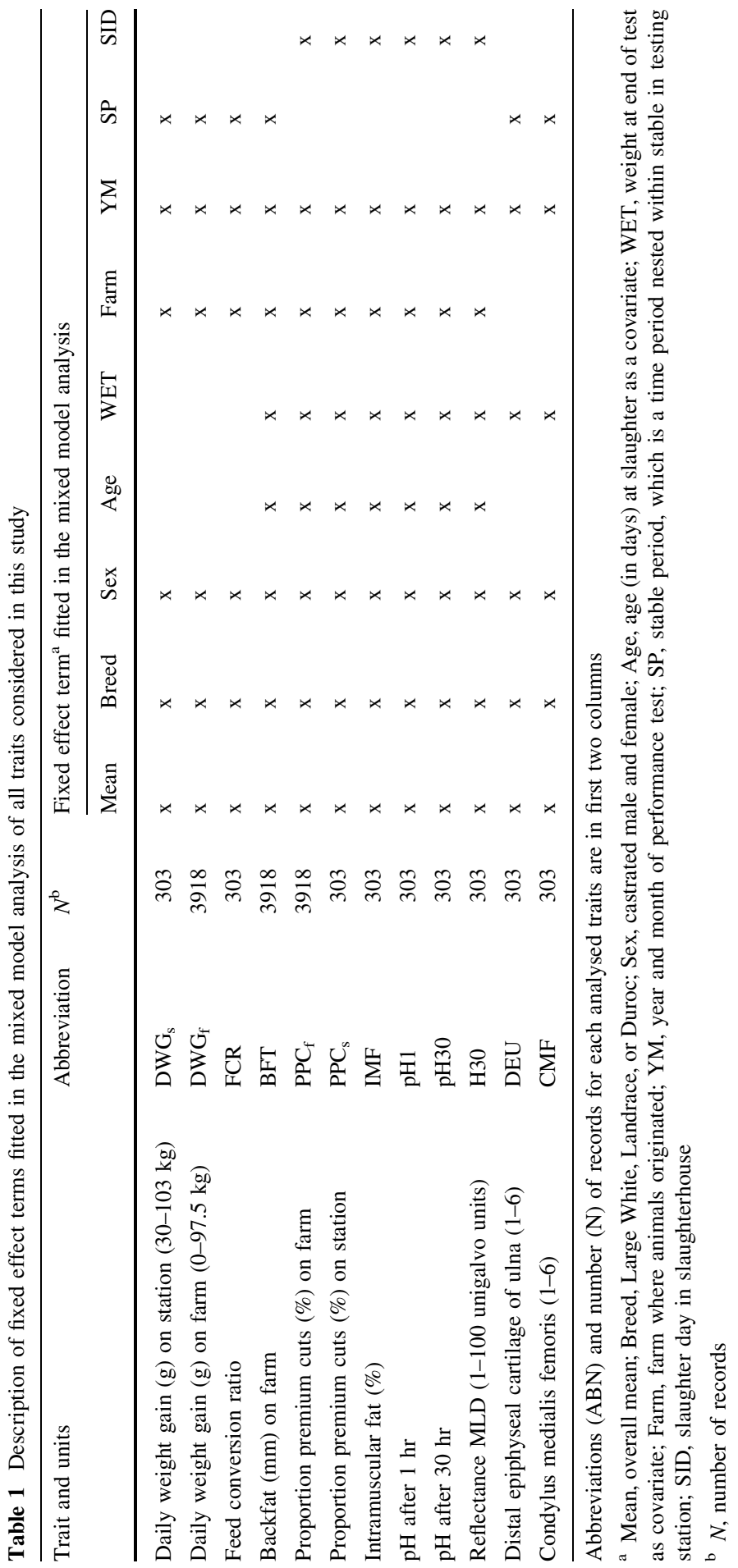



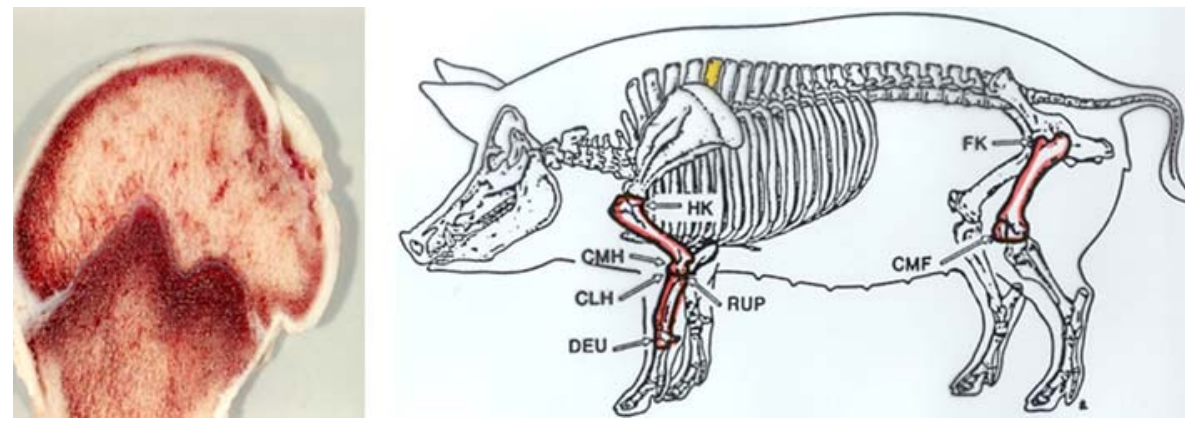

Fig. 1 Osteochondral (OC) lesions in pig. Left: head of humerus bone showing the OC lesions. Right: pig skeleton showing joints where OC lesions are scored (from Kadarmideen et al. 2004)

combinations. The matrix $W$ is a $r \times c$ design matrix, with $r=$ number of records and $c=$ number of unique alleles at the locus; each element of $W$ contains a number of copies of a given allele $(0,1$, or 2$)$, and $g$ is an allele substitution effect (linear effect of substituting 0 or 1 or 2 copies of a given allele for the other allele at the same locus). The regression on the count of allele provides effect of linear increase in allele effects on traits (e.g., Sharif et al. 1998). In the actual analysis, the missing class effect was included and estimated for each locus, and the effect of one allele was set to zero effect due to linear dependency in estimating allelic effects. Estimation of genetic and environmental parameters was performed by single-trait analysis. There were 12 traits by 12 marker mixed model analyses (144 total), for which ASReml software (Gilmour et al. 2002) was used. An F-ratio test statistic and the associated $P$-values for each one of the 144 analyses were collated to determine significance.

\section{Results and Discussion}

Phenotypic and Genetic Properties of Production and Osteochondral Traits

Mean and standard deviations (SD) for all traits used in the analysis are given in Table 2, along with their univariate estimate of heritability $\left(h^{2}\right)$ and standard error (s.e.). Heritability estimates for production, FCR, and IMF traits were high compared to those for $\mathrm{pH}$ and osteochondral lesions. Heritability estimates were $0.21-0.28$ (Table 2) for daily weight gain, which is similar to estimates reported by Hermesch et al. (2000). Hermesch et al. (2000) further reported that estimates of heritability for most meat quality traits ranged from 0.14 to 0.35 , which agrees with our findings. Heritability estimates for IMF (0.66) were higher than for the other meat quality traits $(0.12-0.24)$. These descriptive statistics as well as heritability estimates were very similar to those obtained from earlier analyses of the same dataset, including osteochondral lesions (Kadarmideen et al. 2004). In this study, heritability estimates for three additional traits recorded on-farm are reported 
Table 2 Heritability of production and osteochondral traits in pigs analyzed by allele substitution mixed models

\begin{tabular}{llrrrr}
\hline Trait and units & Abbreviation & $N$ & Mean & $\mathrm{SD}$ & $h^{2}(\mathrm{s.e.})^{\mathrm{a}}$ \\
\hline Daily weight gain (g) on station (30-103 kg) & $\mathrm{DWG}_{\mathrm{s}}$ & 303 & 882.81 & 85.31 & $0.21(0.07)$ \\
Daily weight gain (g) on farm (0-97.5 kg) & $\mathrm{DWG}_{\mathrm{f}}$ & 3918 & 605.0 & 51.21 & $0.28(0.07)$ \\
Feed conversion ratio & $\mathrm{FCR}$ & 303 & 2.54 & 0.14 & $0.42(0.07)$ \\
Backfat (mm) on farm & $\mathrm{BFT}$ & 3918 & 10.6 & 1.42 & $0.43(0.08)$ \\
Proportion premium cuts (\%) on farm & $\mathrm{PPC}_{\mathrm{f}}$ & 3918 & 58.20 & 1.51 & $0.60(0.08)$ \\
Proportion premium cuts (\%) on station & $\mathrm{PPC}_{\mathrm{s}}$ & 303 & 57.20 & 2.45 & $0.54(0.28)$ \\
Intramuscular fat (\%) & $\mathrm{IMF}$ & 303 & 2.12 & 0.56 & $0.66(0.18)$ \\
pH after 1 h & $\mathrm{pH} 1$ & 303 & 6.27 & 0.16 & $0.12(0.07)$ \\
pH after 30 h & $\mathrm{pH} 30$ & 303 & 5.41 & 0.06 & $0.18(0.09)$ \\
Reflectance MLD (1-100 unigalvo units) & $\mathrm{H} 30$ & 303 & 32.73 & 3.08 & $0.24(0.12)$ \\
Distal epiphyseal cartilage of ulna (1-6) & $\mathrm{DEU}$ & 303 & 2.31 & 0.83 & $0.06(0.06)$ \\
Condylus medialis femoris (1-6) & $\mathrm{CMF}$ & 303 & 1.33 & 0.46 & $0.15(0.07)$ \\
\hline
\end{tabular}

${ }^{a}$ Univariate estimate of heritability (with s.e.)

$\left(\mathrm{DWG}_{\mathrm{f}}, \mathrm{BFT}\right.$, and $\left.\mathrm{PPC}_{\mathrm{f}}\right)$. Overall, these medium to high heritabilities indicate that these traits have a strong genetic basis and that genetic variation exists in pig populations for further selection and breeding.

\section{Allele Frequencies}

Allele frequencies of 12 marker loci were estimated by simple allele counting at each locus in 3,918 pigs (Table 3). There were missing or unknown genotypes for some of these marker systems (up to $58 \%$ ). Samples were pooled across three breeds in order to obtain a higher sample size for estimation of allele frequency and in accordance with mixed model genetic analysis to estimate additive genetic variation in the entire population. For blood types, allele A was more frequent; for GPI and PGM, allele B was more frequent than allele A; for the Po1A system, alleles A and $\mathrm{B}$ were more frequent. For the $R Y R l$ gene, the stress susceptibility $\mathrm{T}$ allele remains at very low frequency (0.002); it cannot be completely eliminated due to importation of boars that are $\mathrm{T}$ carriers. For the ECF18R gene, the frequency of the resistant A allele was 0.42 and the susceptible $G$ allele was 0.57 , showing that there is still room for selection against susceptible genotypes.

\section{Association Tests and Allelic Effects}

$P$-values from association test results are in Table 4. Most of the markers were not significantly associated with station-tested traits, such as IMF, FCR, DWG, $\mathrm{PPC}_{\mathrm{s}}$, and $\mathrm{H} 30$ (possibly due to low number of records); hence, $P$-values for these traits are not presented in Table 4. Blood groups in general lack significant associations 
Table 3 Allele frequency in Swiss pig populations

\begin{tabular}{|c|c|c|c|c|c|}
\hline Locus $^{a}$ & $N$ & Allele 1 & Allele 2 & Allele 3 & Allele 4 \\
\hline BG-A & 3248 & 0.131 & 0.869 & 0.000 & 0.000 \\
\hline BG-E & 1632 & 0.444 & 0.210 & 0.121 & 0.225 \\
\hline BG-G & 1689 & 0.309 & 0.691 & 0.000 & 0.000 \\
\hline BG-H & 3193 & 0.485 & 0.218 & 0.297 & 0.000 \\
\hline BG-K & 871 & 0.464 & 0.505 & 0.031 & 0.000 \\
\hline BG-S & 1798 & 0.243 & 0.757 & 0.000 & 0.000 \\
\hline $\mathrm{ADA}$ & 79 & 0.716 & 0.284 & 0.000 & 0.000 \\
\hline PGD & 2799 & 0.543 & 0.457 & 0.000 & 0.000 \\
\hline PGM & 1757 & 0.158 & 0.842 & 0.000 & 0.000 \\
\hline GPI & 2881 & 0.477 & 0.523 & 0.000 & 0.000 \\
\hline Po1A & 1686 & 0.702 & 0.214 & 0.002 & 0.083 \\
\hline A1BG & 3758 & 0.511 & 0.489 & 0.000 & 0.000 \\
\hline$R Y R$ & 1302 & 0.998 & 0.002 & 0.000 & 0.000 \\
\hline$E C F 18 R$ & 3507 & 0.468 & 0.532 & 0.000 & 0.000 \\
\hline
\end{tabular}

${ }^{\mathrm{a}} \mathrm{BG}$, blood group; enzyme; protein; RYR and ECF18R gene polymorphisms

Table 4 P-value of association between polymorphisms and traits in pigs using allele substitution mixed model

\begin{tabular}{|c|c|c|c|c|c|c|c|c|}
\hline \multirow[t]{2}{*}{ Locus $^{\mathrm{a}}$} & \multirow[t]{2}{*}{$N$} & \multicolumn{7}{|c|}{ Production trait or osteochondral disease ${ }^{b}$} \\
\hline & & $\mathrm{DWG}_{\mathrm{f}}$ & $\mathrm{PPC}_{\mathrm{f}}$ & BFT & $\mathrm{pH} 1$ & pH30 & DEU & $\mathrm{CMF}$ \\
\hline BG-A & 3248 & 0.2866 & $0.0722^{*}$ & 0.2086 & 0.5833 & 0.3654 & 0.2360 & 0.5695 \\
\hline BG-S & 1798 & 0.6126 & 0.5712 & 0.6065 & $0.0405^{* *}$ & 0.1559 & 0.5268 & $0.0062^{* * *}$ \\
\hline BG-H & 3193 & $0.0018^{* * *}$ & $0.0057^{* * *}$ & $0.0030^{* * *}$ & $0.0192^{* *}$ & 0.2305 & 0.8894 & $0.0377^{* *}$ \\
\hline BG-G & 1689 & 0.7047 & 0.7041 & 0.9139 & 0.2433 & $0.0434^{* *}$ & 0.3642 & 0.1839 \\
\hline BG-E & 1632 & 0.1219 & $0.0442^{* *}$ & $0.0104^{* *}$ & 0.3519 & 0.7578 & 0.9227 & 0.2000 \\
\hline GPI & 2881 & $0.0945^{*}$ & $0.0977^{*}$ & $0.0899^{*}$ & 0.8188 & 0.8107 & $0.0038^{* * *}$ & $0.0235^{* *}$ \\
\hline PGD & 2799 & $0.0456^{* *}$ & 0.4677 & 0.2726 & 0.1329 & 0.6717 & 0.8241 & $0.0459^{* * *}$ \\
\hline PGM & 1757 & 0.3946 & 0.2020 & 0.2467 & 0.4458 & 0.4876 & $0.0210^{* *}$ & $0.0434^{* * *}$ \\
\hline Po1A & 1686 & $0.0229^{* *}$ & $0.0094^{* * *}$ & $0.0020^{* * *}$ & $0.0822^{*}$ & $0.0690^{*}$ & $0.0113^{* *}$ & $0.0358^{* *}$ \\
\hline A1BG & 3758 & $0.0003^{* * *}$ & 0.1467 & 0.1467 & $0.0998^{*}$ & $0.0624^{*}$ & $0.0802^{*}$ & $0.0657^{* *}$ \\
\hline$R Y R$ & 1302 & $0.0000^{\text {****}}$ & $0.0000^{\text {**** }}$ & $0.0000^{* * *}$ & $0.0161^{* *}$ & $0.0075^{* *}$ & $0.0166^{* *}$ & $0.0100^{* *}$ \\
\hline$E C F 18 R$ & 3507 & $0.0700^{*}$ & $0.0479^{* *}$ & $0.0562^{*}$ & 0.3654 & 0.4414 & $0.0765^{*}$ & $0.0199^{* * *}$ \\
\hline
\end{tabular}

${ }^{a}$ BG, blood group; enzyme; protein; RYR and E. coli

b Abbreviations as in Table 1

* Significant association between trait and marker at $P<0.10$

** Significant association between trait and marker at $P<0.05$

*** Significant association between trait and marker at $P<0.001$ 
with many of the traits analyzed, except $\mathrm{H}$ and $\mathrm{S}$ types. Enzyme and protein show significant associations, mostly with $\mathrm{DWG}_{\mathrm{f}}, \mathrm{PPC}_{\mathrm{f}}$, and BFT. The $R Y R$ gene significantly affected all on-farm traits, $\mathrm{pH}$, and osteochondral lesions.

\section{Marker Effects on Growth, Meat Quality, and Meat Quantity}

Actual allele substitution effects at all loci are given in Table 5, but only for traits where it was mostly statistically significant. Associations between blood group types and various production and meat quality traits were mostly nonsignificant, except for $\mathrm{S}$ and $\mathrm{H}$ types. GPI allele B decreases weight gain and meat quantity but increases backfat and $\mathrm{pH}$ values. Proteins Po1A and A1BG affected not only onfarm traits but also $\mathrm{pH}$ and osteochondral lesions. A1BG allele $\mathrm{S}$, in relation to the $\mathrm{F}$ allele, was associated with increased $\mathrm{DWG}_{\mathrm{f}}$ and $\mathrm{BFT}$, decreased $\mathrm{PPC}_{\mathrm{f}}$, and decreased osteochondral lesions. The A1BG-S allele seems to decrease $\mathrm{pH}$ values of muscle. The $R Y R-\mathrm{C}$ allele decreases growth and premium cuts and increases BFT, in relation to the $\mathrm{T}$ allele. The recessive $\mathrm{T}$ allele decreases $\mathrm{pH} 1$ and $\mathrm{pH} 30$ values, typical findings of the halothane gene; this is confirmed here by the opposite effect of the $R Y R-\mathrm{C}$ allele. These effects correspond to previous reports of $R Y R l$ gene C-T allele effects on growth and meat quality traits in pigs (e.g., Zhang et al. 1992) The ECF 18R-A allele increases growth and BFT but decreases premium cuts, in relation to the $\mathrm{G}$ allele. The association with meat quality and growth seems to be in line with biological expectation for RYR and EcoliF18 genotypes. Meijerink et al. (1997) reported that the ECF18R locus is closely linked to two fucosyltransferase genes (FUT1 and FUT2) and suggested that the polymorphisms in these genes, especially at bp 307 of FUT1, can be used in marker-assisted selection of pigs for susceptibility to diarrhea. This marker could also be used in selection indirectly via the strong association of the ECF18R gene with some of the growth traits we analyzed.

\section{Marker Effects on Osteochondral Diseases}

Detection of marker allele association with OC lesions would be very helpful in marker-assisted selection because osteochondral lesions are difficult to select using conventional animal breeding methods. The reasons for this include low heritability and difficulty in widespread recording in animal populations. Statistically significant association results in Table 5 show that the following alleles ay be used as markers to reduce the incidence of this disease. On a scale of $1-6$, the effects of allele substitution were as follows. The GPI allele B reduces the incidence by 0.094 units in DEU and by 0.033 units in CMF, compared to the A allele at the GPI locus. Po1A allele D reduced the DEU lesion by 1.065 units and the CMF lesion 0.179 units. A1BG allele $S$, in relation to the $\mathrm{F}$ allele, reduced the DEU lesion by 0.104 units and the $\mathrm{CMF}$ by 0.153 units. The blood group $\mathrm{H}$ allele A reduced CMF by 0.365 units, but its effect on DEU was not significant; the opposite is true for the $\mathrm{N}$ allele (it reduced $\mathrm{DEU}$ but not $\mathrm{CMF}$ ). The $\mathrm{C}$ allele at the $R Y R l$ gene had a very large 


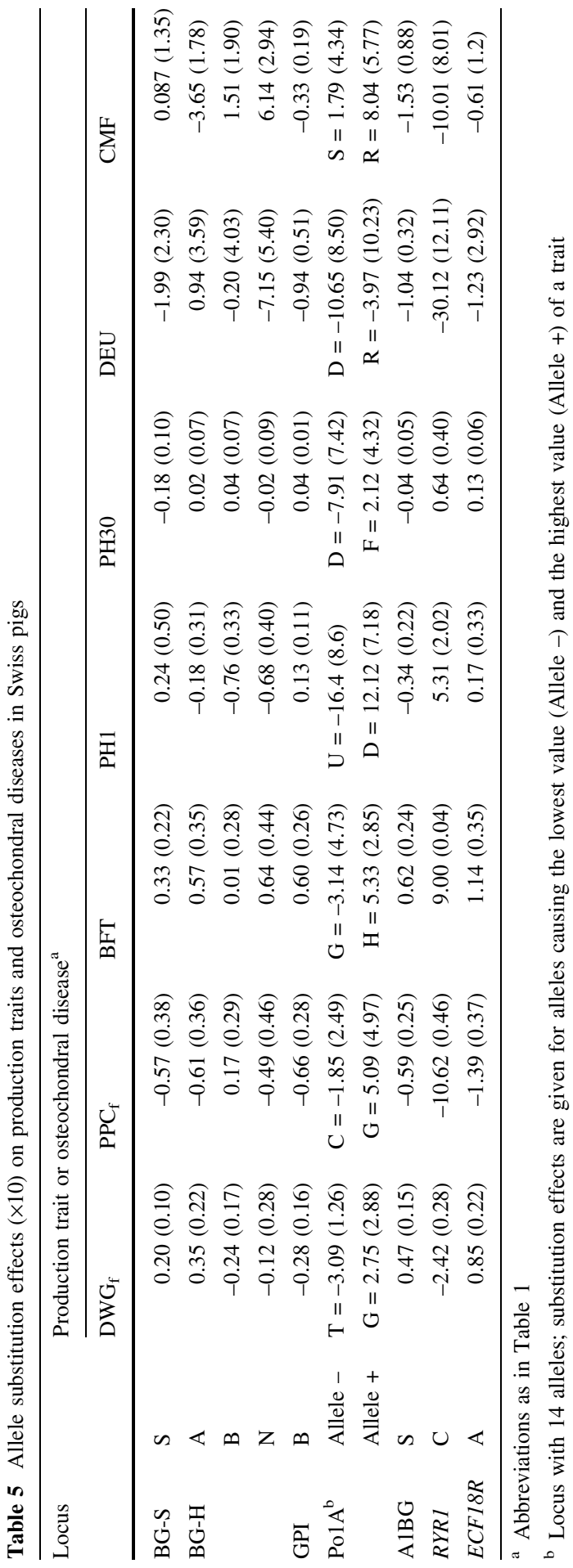


effect on osteochondral lesions: it reduced DEU by nearly 3 units and CMF by 1.01 units. The A allele at ECF18R also had effects on osteochondral lesions, but the results were not statistically significant. These findings have never been made before, and hence no literature estimates are available for discussion. The biological basis of the relationship between osteochondral lesions and these markers needs further investigation at the level of proteomics and metabolomics.

Note that the allele substitution effects given in Table 5 are multiplied by 10 , and hence true differences between alternate alleles at any locus should be divided by 10. For instance, the effect of the $R Y R l$ gene $\mathrm{C}$ allele reduces $\mathrm{DWG}_{\mathrm{f}}$ by $0.2 \mathrm{~g}, \mathrm{PPC}_{\mathrm{f}}$ by $1.0 \mathrm{~g}$, BFT by $0.9 \mathrm{~mm}, \mathrm{pH} 1$ by 0.5 , and $\mathrm{pH} 30$ by 0.06 , relative to the effect of the $\mathrm{T}$ allele on these traits. The major effect is, however, found on osteochondral lesions reducing the osteochondral scores by 3 and 1 (on a scale of 1-6) for DEU and $\mathrm{CMF}$, respectively. In the case of $E C F 18 R$, we find a similar pattern of no large differences between allelic effects on any of the traits. In the specific case of the $R Y R 1$ gene, the allele frequency is the major factor affecting the results; the frequency of the RYRI allele $\mathrm{T}$ was only 0.002 and was exclusively in the heterozygote form. In the allele substitution model, the actual comparison of the allele effect was extracted from a comparison of the genotypes $\mathrm{C} / \mathrm{C}$ and $\mathrm{C} / \mathrm{T}$, while the average phenotype of the heterozygote $\mathrm{C} / \mathrm{T}$ was very similar to the average phenotype of the homozygote $\mathrm{C} / \mathrm{C}$ (sometimes better as the substitution effect tends to show in Table 5). This indicates the dominance effect at this locus. Other loci/ systems (except blood groups) were examined for evidence of dominance, and the results showed that some degree of dominance exists for ADA, PGM, and Po1A, where the genotype means that heterozygotes were similar/superior to homozygotes.

In general, allele substitution effects tended to have a larger standard error for station-tested traits than for on-farm traits (Table 5), which may be due to low sample size as well as to the statistical method used (a mixed model to estimate variance components). It must be noted that loci $S, H, G P I, P G D, A 1 B G, R Y R$, and $E C F 18 R$ are located on porcine chromosome 6 and close linkage (recombination rate less than 0.15 ) has been reported for most of them by Vögeli et al. (1994). Hence, the associations and substitution effects reported here might be statistically confounded. However, given that physical distances between most of these loci are sufficiently large in terms of bp or kb, at the molecular level, these effects would be considered significantly independent and different. The results in this study are similar to situations where effects of candidate genes are confounded by another gene on the same chromosome or by a gene in strong linkage disequilibrium located elsewhere on the genome, affecting the same trait of interest. Theoretically, one can check whether the significance of the loci on any given trait is affected by including chromosomal regions as a fixed effect, but such a model is overparameterized in our case, with 12 markers fitted simultaneously in a multiple marker regression to explain a variation in a single trait. Further, such a close linkage between loci makes the independence of explanatory variables dubious. Hence, this approach was not taken. Note that this is over and above fitting polygenetic effects of sires under the mixed model framework.

It is known that the RYRI and ECF18R genes have significant effects on meat quality and growth, respectively, but very few studies have investigated this in the 
population genetics and mixed model context; this is the first report for Swiss pig populations. The substantial contribution of this study is its report of the associations of osteochondral lesions with 12 biochemical and DNA markers and allelic effects on this disease. This is also true for some growth and meat quality traits.

In conclusion, this study reports many new associations, specifically for the first time on the association between the incidence of two osteochondral lesions and GPI, PGD, Po1A, RYR, and ECF18R, which has potential value for other livestock species and humans. These association results may serve as a basis for further molecular genetic, genomic, and proteomic investigations.

Acknowledgments The author thanks the SuisAG company for provision of trait data and Dr. Peter Vögeli at ETH Zurich, Switzerland, for geno- and phenotyping and for useful discussions.

\section{References}

Fujii J, Otsu K, Zorzato f, Deleon S, Khanna VK, Weiler JE, Obrien PJ, Maclennan DH (1991) Identification of a mutation in porcine ryanodine receptor associated with malignant hyperthermia. Science 253:448-451

Gilmour AR, Gogel BJ, Cullis BR, Welham SJ, Thompson R (2002) ASReml User Guide Release 1.0. VSN International Ltd., Hemel Hempstead, UK

Hermesch S, Luxford BG, Graser HU (2000) Genetic parameters for lean meat yield, meat quality, reproduction and feed efficiency traits for Australian pigs: 1. Description of traits and heritability estimates. Livest Prod Sci 65:239-248

Houde A, Pommier SA, Roy R (1993) Detection of the ryanodine receptor mutation associated with malignant hyperthermia in purebred swine populations. J Anim Sci 71:1414-1418

Hu ZL, Dracheva S, Jang W, Maglott D, Bastiaansen J, Rothschild MF, Reecy JM (2005) A QTL resource comparison tool for pigs: PigQTLDB. Mamm Genome 15:792-800

Jørgensen B (1995) Effect of different energy and protein levels on leg weakness and osteochondrosis in pigs. Livest Prod Sci 41:171-181

Kadarmideen HN, Janss LLG (2005) Evidence of major gene for osteochondral disease in pigs from a bayesian segregation analysis. Genetics 171:1195-1206

Kadarmideen HN, Janss LLG (2007) Population and systems genetics analyses of cortisol in pigs divergently selected for stress. Physiol Genomics 29:57-65

Kadarmideen HN, Janss LLG, Dekkers JCM (2000) Power of quantitative trait locus mapping for polygenic binary traits using generalized and regression interval mapping in multi-family half-sib designs. Genet Res 76:305-317

Kadarmideen HN, Rekaya R, Gianola D (2001) Genetic parameters for clinical mastitis in HolsteinFriesians: a bayesian analysis. Anim Sci 73:229-240

Kadarmideen HN, Schwörer D, Ilahi H, Malek M, Hofer A (2004) Genetics of osteochondral disease and its relationship with meat quality and quantity, growth and feed conversion traits in pigs. J Anim Sci $82: 3118-3127$

Kadarmideen HN, Von Rohr P, Janss LLG (2006) From genetical-genomics to systems genetics: potential applications in quantitative genomics and animal breeding. Mamm Genome 17:548-564

Lahucky R, Christian LL, Kovac L, Stalder KJ, Bauerova M (1997) Meat quality assessed ante- and post mortem by different ryanodine receptor gene status of pigs. Meat Sci 47:277-285

Larzul C, LeRoy P, Gueblez R, Talmant A, Gogue J, Sellier P, Monin G (1997) Effect of halothane genotype (NN, Nn, nn) on growth, carcass and meat quality traits of pigs slaughtered at $95 \mathrm{~kg}$ or $125 \mathrm{~kg}$ live weight. J Anim Breed Genet 114:309-320

Lundeheim N (1987) Genetic analysis of osteochondrosis and leg weakness in the Swedish pig progeny testing scheme. Acta Agric Scand 37:159-173

Meijerink E, Fries R, Vogeli P, Masabanda J, Wigger G, Stricker C, Neuenschwander S, Bertschinger HU, Stranzinger G (1997) Two alpha(1,2) fucosyltransferase genes on porcine chromosome $6 \mathrm{q} 11$ 
are closely linked to the blood group inhibitor (S) and Escherichia coli $\mathrm{F} 18$ receptor (ECF18R) loci. Mamm Genome 8:736-741

Murray AC, Johnson CP (1998) Impact of the halothane gene on muscle quality and pre-slaughter deaths in western Canadian pigs. Canadian J Anim Sci 78:543-548

Otsu K, Khanna VK, Archibald AL, Maclennan DH (1991) Cosegregation of porcine malignant hyperthermia and a probable causal mutation in the skeletal-muscle ryanodine receptor gene in backcross families. Genomics 11:744-750

Rothschild MF, Christian LL, Jung YC (1988) Genetic control of front-leg weakness in Duroc swine. II. Correlated responses in growth rate, backfat and reproduction from five generations of divergent selection. Livest Prod Sci 19:473-485

Sharif S, Mallard BA, Wilkie BN, Sargeant JM, Scott HM, Dekkers JCM, Leslie KE (1998) Associations of the bovine major histocompatibility complex DRB3 (BoLA-DRB3) alleles with occurrence of disease and milk somatic cell score in Canadian dairy cattle. Anim Genet 29:185-193

Vögeli P, Bolt R, Fries R, Stranzinger G (1994) Co-segregation of the malignant hyperthermia and the $\arg (615)$-cys(615) mutation in the skeletal-muscle calcium-release channel protein in 5 European landrace and pietrain pig breeds. Anim Genet 25(Suppl 1):59-66

Vögeli P, Bertschinger HU, Stamm M, Stricker C, Hagger C, Fries R, Rapacz J, Stranzinger G (1996) Genes specifying receptors for F18 fimbriated Escherichia coli, causing oedema disease and postweaning diarrhoea in pigs, map to chromosome 6. Anim Genet 27:321-328

Zhang W, Kuhlers DL, Rempel E (1992) Halothane gene and swine performance. J Anim Sci 70:13071313 